\title{
Effects of off-pump and on-pump coronary-artery bypass grafting at 1 year
}

Lamy, André ; Devereaux, P J ; Prabhakaran, Dorairaj ; Taggart, David P ; Hu, Shengshou ; Paolasso, Ernesto ; Straka, Zbynek ; Piegas, Leopoldo S ; Akar, Ahmet Ruchan ; Jain, Anil R ; Noiseux, Nicolas ; Padmanabhan, Chandrasekar ; Bahamondes, Juan-Carlos ; Novick, Richard J ; Vaijyanath, Prashant ; Reddy, Sukesh Kumar ; Tao, Liang ; Olavegogeascoechea, Pablo A ; Airan, Balram ; Sulling, Toomas-Andres ; Whitlock, Richard P ; Ou, Yongning ; Pogue, Janice ; Chrolavicius, Susan ; Yusuf, Salim

\begin{abstract}
BACKGROUND: Previously, we reported that there was no significant difference at 30 days in the rate of a primary composite outcome of death, myocardial infarction, stroke, or new renal failure requiring dialysis between patients who underwent coronary-artery bypass grafting (CABG) performed with a beating-heart technique (off-pump) and those who underwent CABG performed with cardiopulmonary bypass (on-pump). We now report results on quality of life and cognitive function and on clinical outcomes at 1 year. METHODS: We enrolled 4752 patients with coronary artery disease who were scheduled to undergo CABG and randomly assigned them to undergo the procedure off-pump or on-pump. Patients were enrolled at 79 centers in 19 countries. We assessed quality of life and cognitive function at discharge, at 30 days, and at 1 year and clinical outcomes at 1 year. RESULTS: At 1 year, there was no significant difference in the rate of the primary composite outcome between off-pump and on-pump CABG (12.1\% and 13.3\%, respectively; hazard ratio with off-pump CABG, $0.91 ; 95 \%$ confidence interval [CI], 0.77 to $1.07 ; \mathrm{P}=0.24)$. The rate of the primary outcome was also similar in the two groups in the period between 31 days and 1 year (hazard ratio, $0.79 ; 95 \% \mathrm{CI}, 0.55$ to $1.13 ; \mathrm{P}=0.19$ ). The rate of repeat coronary revascularization at 1 year was $1.4 \%$ in the off-pump group and $0.8 \%$ in the on-pump group (hazard ratio, $1.66 ; 95 \% \mathrm{CI}, 0.95$ to $2.89 ; \mathrm{P}=0.07$ ). There were no significant differences between the two groups at 1 year in measures of quality of life or neurocognitive function. CONCLUSIONS: At 1 year after CABG, there was no significant difference between off-pump and on-pump CABG with respect to the primary composite outcome, the rate of repeat coronary revascularization, quality of life, or neurocognitive function. (Funded by the Canadian Institutes of Health Research; CORONARY ClinicalTrials.gov number, NCT00463294.).
\end{abstract}

DOI: https://doi.org/10.1056/NEJMoa1301228

Posted at the Zurich Open Repository and Archive, University of Zurich

ZORA URL: https://doi.org/10.5167/uzh-91417

Journal Article

Published Version

Originally published at:

Lamy, André; Devereaux, P J; Prabhakaran, Dorairaj; Taggart, David P; Hu, Shengshou; Paolasso, Ernesto; Straka, Zbynek; Piegas, Leopoldo S; Akar, Ahmet Ruchan; Jain, Anil R; Noiseux, Nicolas; Padmanabhan, Chandrasekar; Bahamondes, Juan-Carlos; Novick, Richard J; Vaijyanath, Prashant; Reddy, 
Sukesh Kumar; Tao, Liang; Olavegogeascoechea, Pablo A; Airan, Balram; Sulling, Toomas-Andres; Whitlock, Richard P; Ou, Yongning; Pogue, Janice; Chrolavicius, Susan; Yusuf, Salim (2013). Effects of off-pump and on-pump coronary-artery bypass grafting at 1 year. New England Journal of Medicine, 368(13):1179-1188.

DOI: https://doi.org/10.1056/NEJMoa1301228 


\title{
The NEW ENGLAN D \\ JOURNAL of MEDICINE
}

ESTABLISHED IN 1812

MARCH 28, 2013

VOL. 368 NO. 13

\section{Effects of Off-Pump and On-Pump Coronary-Artery Bypass Grafting at 1 Year}

\author{
André Lamy, M.D., P.J. Devereaux, M.D., Ph.D., Dorairaj Prabhakaran, M.D., David P. Taggart, Ph.D., \\ Shengshou Hu, M.D., Ernesto Paolasso, M.D.,* Zbynek Straka, M.D., Leopoldo S. Piegas, M.D., \\ Ahmet Ruchan Akar, M.D., Anil R. Jain, M.D., Nicolas Noiseux, M.D., Chandrasekar Padmanabhan, M.D., \\ Juan-Carlos Bahamondes, M.D., Richard J. Novick, M.D., Prashant Vaijyanath, M.D., Sukesh Kumar Reddy, M.D., \\ Liang Tao, M.D., Pablo A. Olavegogeascoechea, M.D., Balram Airan, M.D., Toomas-Andres Sulling, M.D., \\ Richard P. Whitlock, M.D., Yongning Ou, M.Sc., Janice Pogue, Ph.D., Susan Chrolavicius, B.A., \\ and Salim Yusuf, D.Phil., for the CORONARY Investigators $†$ '
}

\section{A BSTRACT}

\section{BACKGROUND}

Previously, we reported that there was no significant difference at 30 days in the rate of a primary composite outcome of death, myocardial infarction, stroke, or new renal failure requiring dialysis between patients who underwent coronary-artery bypass grafting (CABG) performed with a beating-heart technique (off-pump) and those who underwent CABG performed with cardiopulmonary bypass (on-pump). We now report results on quality of life and cognitive function and on clinical outcomes at 1 year.

\section{METHODS}

We enrolled 4752 patients with coronary artery disease who were scheduled to undergo CABG and randomly assigned them to undergo the procedure off-pump or on-pump. Patients were enrolled at 79 centers in 19 countries. We assessed quality of life and cognitive function at discharge, at 30 days, and at 1 year and clinical outcomes at 1 year.

\section{RESULTS}

At 1 year, there was no significant difference in the rate of the primary composite outcome between off-pump and on-pump CABG (12.1\% and 13.3\%, respectively; hazard ratio with off-pump CABG, 0.91; 95\% confidence interval [CI], 0.77 to 1.07; $\mathrm{P}=0.24)$. The rate of the primary outcome was also similar in the two groups in the period between 31 days and 1 year (hazard ratio, $0.79 ; 95 \%$ CI, 0.55 to $1.13 ; \mathrm{P}=0.19$ ). The rate of repeat coronary revascularization at 1 year was $1.4 \%$ in the off-pump group and $0.8 \%$ in the on-pump group (hazard ratio, 1.66; $95 \%$ CI, 0.95 to 2.89; $\mathrm{P}=0.07$ ). There were no significant differences between the two groups at 1 year in measures of quality of life or neurocognitive function.

\section{CONCLUSIONS}

At 1 year after CABG, there was no significant difference between off-pump and on-pump CABG with respect to the primary composite outcome, the rate of repeat coronary revascularization, quality of life, or neurocognitive function. (Funded by the Canadian Institutes of Health Research; CORONARY ClinicalTrials.gov number, NCT00463294.)
The authors' affiliations are listed in the Appendix. Address reprint requests to Dr. Lamy at the Population Health Research Institute, Hamilton Health Sciences, McMaster University, Hamilton, ON L8L 2X2, Canada, or at lamya@mcmaster.ca.

$*$ Deceased.

$\uparrow$ Investigators in the CABG Off or On Pump Revascularization Study (CORONARY) are listed in the Supplementary Appendix, available at NEJM.org.

This article was published on March 11, 2013, at NEJM.org.

N Engl J Med 2013;368:1179-88. DOI: 10.1056/NEJMoal301228

Copyright (๑) 2013 Massachusetts Medical Society. 
ORONARY-ARTERY BYPASS GRAFTING (CABG) reduces mortality among patients with extensive coronary artery disease. ${ }^{1}$ CABG is usually performed with the use of cardiopulmonary bypass (on-pump CABG). With this approach, perioperative mortality is about $2 \%$, and myocardial infarction, stroke, or renal failure requiring dialysis develop in an additional 5 to $7 \%$ of patients. The technique of performing CABG on a beating heart (off-pump CABG) was developed to reduce perioperative complications, some of which may be related to the use of cardiopulmonary bypass and to the cross-clamping of the aorta associated with the on-pump CABG procedure, and to improve long-term outcomes.

A number of trials have compared off-pump CABG with on-pump CABG. ${ }^{2-6}$ Among the largest trials are the Randomized On/Off Bypass $(\mathrm{ROOBY})^{7,8}$ trial, which enrolled 2203 patients from the Veterans Affairs medical system, and the Danish On-Pump versus Off-Pump Randomization Study (DOORS), which enrolled 900 patients. ${ }^{9,10}$ Neither of these trials had sufficient power to accurately assess moderate but clinically important differences between the groups with respect to death, myocardial infarction, stroke, or renal failure. As shown in a number of smaller trials, ${ }^{11-14}$ the skills of the participating surgeons can influence the outcome of a specific surgical procedure, and the level of surgical expertise required by the protocol, particularly for the offpump procedure, varied among these trials.

To evaluate the effects of off-pump CABG as compared with on-pump CABG, we conducted a large, international trial - the CABG Off or On Pump Revascularization Study (CORONARY) — in which 4752 patients were enrolled. To overcome some of the limitations of prior trials, we conducted the trial at a wider range of hospital types than those in the previous trials and included only experienced surgeons. Previously we reported the 30-day outcomes of the trial. ${ }^{15}$ The rate of the primary outcome (a composite of death, myocardial infarction, stroke, or new renal failure requiring dialysis) was similar in the two groups at 30 days. The rate of repeat revascularization (percutaneous coronary intervention $[\mathrm{PCI}]$ or $\mathrm{CABG}$ ) early after CABG (<30 days after randomization) was higher in the off-pump group. The rates of bleeding, acute kidney injury, and respiratory complications were lower with off-pump CABG than with on-pump CABG.
Similar to the results of CORONARY, the results of the ROOBY trial showed no significant difference in the 30-day primary outcome; in the ROOBY trial, however, the rate of the primary composite outcome at 1 year (death from any cause, repeat revascularization, or nonfatal myocardial infarction) was higher with off-pump CABG than with on-pump CABG. Because the 1-year results in the ROOBY trial have raised concern about the value of off-pump surgery, we report the 1-year results in CORONARY.

METHODS

\section{TRIAL DESIGN}

CORONARY was a randomized, controlled trial, with blinded adjudication of outcomes, that compared off-pump CABG with on-pump CABG among patients undergoing isolated CABG. The primary hypothesis was that the rate of major clinical events would be lower with off-pump CABG than with on-pump CABG in the short term (30 days) and that the benefits would be maintained in the long term (5 years). The study protocol has been published previously ${ }^{16}$ and is also available with the full text of this article at NEJM.org. The 30-day results have also been published previously. ${ }^{15}$

The trial was designed by the authors and approved by national regulatory authorities and by the ethics committee at each participating center. The data were gathered and analyzed by the Population Health Research Institute (McMaster University, Hamilton, Ontario, Canada). All the authors vouch for the accuracy and completeness of the data and analyses and for the fidelity of this report to the trial protocol.

\section{PATIENTS}

Patients who were scheduled to undergo CABG were eligible to participate in the trial if they required isolated CABG with median sternotomy and had one or more of the following risk factors: an age of 70 years or more, peripheral arterial disease, cerebrovascular disease or carotid stenosis of $70 \%$ or more of the luminal diameter, or renal insufficiency. Patients 60 to 69 years of age were eligible if they had at least one of the following risk factors: diabetes requiring treatment with an oral hypoglycemic agent or insulin, the need for urgent revascularization after an acute coronary syndrome, a left ventricular ejec- 
tion fraction of $35 \%$ or less, or a recent history of smoking ( $<1$ year before randomization); patients 55 to 59 years of age were eligible if they had at least two of those risk factors. All patients were required to provide written informed consent.

\section{QUALIFICATION OF SURGEONS}

To ensure that surgeons were skilled in the technique assigned, we used the approach of an expertise-based, randomized, controlled trial. ${ }^{17}$ Each procedure was performed by a surgeon with expertise in the specific type of surgery that the patient was assigned to undergo. A surgeon was considered to have expertise if he or she had more than 2 years of experience after residency training and had completed more than 100 cases of the specific technique (either on-pump or off-pump CABG). Surgeons who met these criteria for each type of operation separately were considered to have expertise in both techniques and were allowed to perform both types of CABG surgery during the trial. Trainees were not allowed to be the primary surgeon.

\section{TRIAL OUTCOMES}

The trial included two coprimary outcomes. The first was a composite rate of death, nonfatal stroke, nonfatal myocardial infarction, or nonfatal new renal failure requiring dialysis at 30 days after randomization. This outcome was also assessed at 1 year. The second coprimary outcome consisted of the first coprimary outcome plus the rate of repeat coronary revascularization at a mean of 5 years. All deaths in the first 30 days were considered to be cardiovascular-related deaths. All reported events of the components of the primary outcome and of recurrent angina were reviewed by an adjudication committee whose members were unaware of the group assignments. The outcome events as adjudicated by that committee were included in the statistical analyses.

We used the European Quality of Life-5 Dimensions questionnaire (EQ-5D) ${ }^{18,19}$ and the EQ-5D visual-analogue scale to assess the quality of life. The EQ-5D score ranges from 0 to 1 , with higher scores indicating a better quality of life. The EQ-5D visual-analogue scale ranges from 0 to 100 , with higher scores indicating a better quality of life.

To assess neurocognitive function, we followed the guidelines on vascular cognitive impairment harmonization standards from the joint National Institute of Neurological Disorders and Stroke-
Canadian Stroke Network (NINDS-CSN). ${ }^{20}$ We used three neurocognitive tests: the Montreal Cognitive Assessment, ${ }^{21}$ the Digit Symbol Substitution Test, ${ }^{22,23}$ and the Trail Making Test Part B. ${ }^{24-26}$ Scores on the Montreal Cognitive Assessment range from 0 to 30, with higher scores indicating better cognitive function. The lowest score on the Digit Symbol Substitution Test is 0 and there is no upper limit; higher scores indicate better cognitive function. The Trail Making Test Part B is a timed test in which a lower score (in seconds) indicates better function.

The quality-of-life and neurocognitive assessments were originally intended to be mandatory for all participants but were made optional early in the course of the trial to improve recruitment. The decision about a patient's participation in these assessments was made on an individual basis; centers could select for these assessments patients who might be more likely to return to the hospital during the follow-up period to complete the tests. The decision to participate was made before randomization, to avoid biases. All the quality-of-life and neurocognitive tests were administered before CABG was performed (before randomization), at the time of discharge, at 30 days, and at 1 year.

\section{STATISTICAL ANALYSIS}

All analyses were conducted according to the intention-to-treat principle. After testing the assumption of proportional hazards, we conducted a time-to-event analysis, using Cox regression to report the 1-year outcomes. The time to the first occurrence of any one of the components of the primary outcome was described with the use of Kaplan-Meier survival curves, and the comparisons between the two study groups were performed with the use of a log-rank test. The treatment effect is expressed as the hazard ratio (with 95\% confidence intervals), which was derived from the Cox proportional-hazards model for the first coprimary outcome at 1 year. The comparison between the two operative techniques was assessed in subgroups defined according to the presence or absence of diabetes, the presence or absence of cerebrovascular disease, left ventricular function, the number of diseased vessels, sex, age, bodymass index, region, and European System for Cardiac Operative Risk Evaluation (EuroSCORE) grade, and tests for interaction were performed with the use of a Cox proportional-hazards model. 


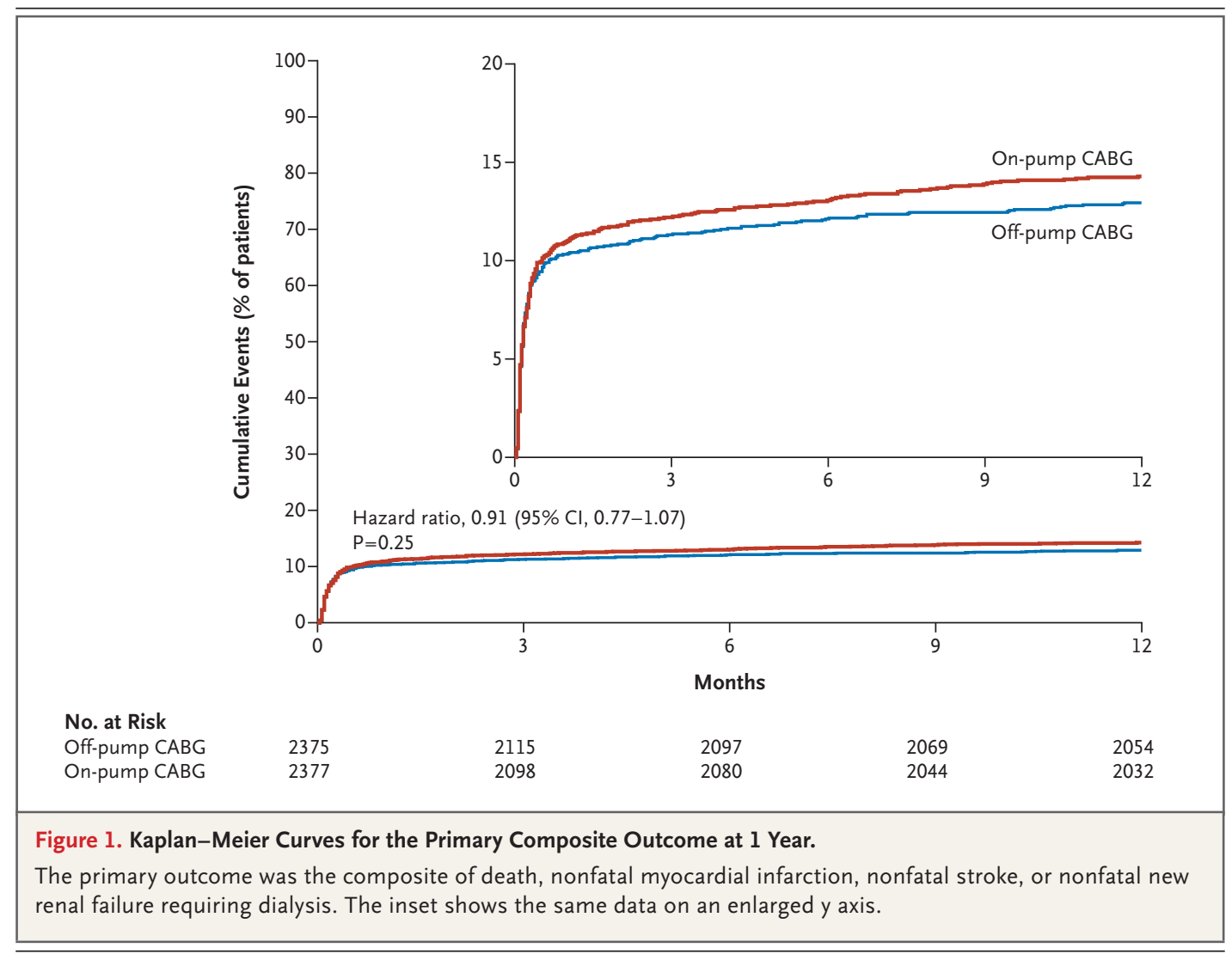

We also conducted landmark analyses assessing these outcomes between 31 days and 1 year; in these analyses, data from patients who had a primary outcome in the first 30 days or who were not followed up after 30 days were not included.

To analyze the quality-of-life and neurocognitive data at each follow-up point (i.e., hospital discharge, 30 days, and 1 year), we calculated the changes in assessment scores from baseline to the follow-up point for each patient, limiting the analysis to patients for whom data were available both at baseline and at the follow-up point being analyzed. The mean value for the change in score was then calculated within each group, ${ }^{27}$ and these means were compared between the two groups.

\section{RESULTS}

\section{PATIENTS}

From November 2006 through October 2011, a total of 4752 patients were enrolled at 79 hospitals in 19 countries and were randomly assigned to undergo either off-pump CABG (2375 patients) or on-pump CABG (2377 patients). The baseline characteristics of the overall trial population have been reported previously and are also provided in Table S1 in the Supplementary Appendix, available at NEJM.org. One-year follow-up data on the clinical outcomes were available for $98.7 \%$ of the patients.

\section{PRIMARY AND OTHER CLINICAL OUTCOMES}

At 1 year, a primary outcome event had occurred in 288 participants $(12.1 \%)$ in the off-pump group and 316 participants (13.3\%) in the on-pump group (hazard ratio with the off-pump procedure, 0.91 ; $95 \%$ confidence interval [CI], 0.77 to 1.07 ; $\mathrm{P}=0.24$ ) (Fig. 1 and Table 1). The rates of individual components of this composite outcome did not differ significantly between the groups. No significant interactions were seen between the procedure and any of the subgroup variables (Fig. 2). There were no significant differences between the off-pump group and the on-pump group in the rates of recurrent angina $(1.0 \%$ and $0.9 \%$, respectively) or in the need for repeat revascularization by means of PCI or CABG $(1.4 \%$ [33 patients] and $0.8 \%$ [20 patients], respectively; haz- 


\begin{tabular}{|c|c|c|c|c|}
\hline Outcome & $\begin{array}{l}\text { Off-Pump CABG } \\
(\mathrm{N}=2375)\end{array}$ & $\begin{array}{l}\text { On-Pump CABG } \\
\quad(N=2377)\end{array}$ & $\begin{array}{l}\text { Hazard Ratio } \\
\text { (95\% CI) }\end{array}$ & P Value \\
\hline Primary outcome - no. (\%) $\dagger$ & $288(12.1)$ & $316(13.3)$ & $0.91(0.77-1.07)$ & 0.24 \\
\hline \multicolumn{5}{|l|}{ Components of primary outcome - no. (\%) } \\
\hline Death & $122(5.1)$ & $119(5.0)$ & $1.03(0.80-1.32)$ & \\
\hline Myocardial infarction & $161(6.8)$ & $178(7.5)$ & $0.90(0.73-1.12)$ & \\
\hline Stroke & $36(1.5)$ & $40(1.7)$ & $0.90(0.57-1.41)$ & \\
\hline New renal failure requiring dialysis & $30(1.3)$ & $31(1.3)$ & $0.97(0.59-1.60)$ & \\
\hline \multicolumn{5}{|l|}{ Other prespecified outcomes — no. (\%) } \\
\hline Cardiovascular-related death & $99(4.2)$ & $96(4.0)$ & $1.03(0.78-1.37)$ & 0.83 \\
\hline Angina & $23(1.0)$ & $22(0.9)$ & $1.05(0.58-1.88)$ & 0.87 \\
\hline \multicolumn{5}{|l|}{ Other outcomes } \\
\hline Repeat revascularization - no. (\%) $\int$ & $33(1.4)$ & $20(0.8)$ & $1.66(0.95-2.89)$ & 0.07 \\
\hline $\mathrm{PCl}$ & $27(1.1)$ & $19(0.8)$ & $1.43(0.79-2.57)$ & 0.23 \\
\hline CABG & $7(0.3)$ & $1(<0.1)$ & $7.00(0.86-57.0)$ & 0.07 \\
\hline $\begin{array}{c}\text { Primary outcome in per protocol population - } \\
\text { no./total no. (\%) }\end{array}$ & 252/2191 (11.5) & $295 / 2227$ (13.2) & $0.86(0.73-1.02)$ & 0.08 \\
\hline
\end{tabular}

* CABG denotes coronary-artery bypass grafting, and PCI percutaneous coronary intervention.

$\uparrow$ The primary outcome was a composite of death, nonfatal stroke, nonfatal myocardial infarction, or new renal failure requiring dialysis.

All deaths in the first 30 days were considered to be cardiovascular-related deaths.

$\int$ One patient underwent both CABG and $\mathrm{PCI}$.

ard ratio, 1.66; $95 \% \mathrm{CI}, 0.95$ to $2.89 ; \mathrm{P}=0.07$ ). The rate of the primary outcome among patients who underwent the assigned procedure (i.e., without crossing over to the other procedure) was similar to the rate in the intention-to-treat population $(11.5 \%$ in the off-pump group and $13.2 \%$ in the on-pump group; hazard ratio, 0.86 ; $95 \%$ CI, 0.73 to $1.02 ; \mathrm{P}=0.08$ ).

The landmark analysis for the period between 31 days and 1 year showed a similar risk of the primary outcome in the two groups: 55 of the 2142 patients in the off-pump group included in this analysis (2.6\%) and 69 of the 2130 patients in the on-pump group included in this analysis (3.2\%) had a primary outcome event (hazard ratio, $0.79 ; 95 \%$ CI, 0.55 to $1.13 ; \mathrm{P}=0.19$ ) (Table 2). These landmark analyses also showed that the rates of recurrent angina and repeat revascularization by means of PCI or CABG were similar in the on-pump and off-pump groups for the period between 31 days and 1 year (recurrent angina: $0.8 \%$ and $0.7 \%$, respectively; hazard ratio, 1.13 ; $95 \%$ CI, 0.56 to 2.26 ; $\mathrm{P}=0.74$; and repeat revascularization: $0.7 \%$ and $0.6 \%$, respectively; hazard ratio, $1.22 ; 95 \% \mathrm{CI}, 0.59$ to $2.54 ; \mathrm{P}=0.59$ ).

\section{QUALITY-OF-LIFE AND NEUROCOGNITIVE OUTCOMES}

A total of 2850 patients initially agreed to provide data for the substudies of quality of life and neurocognitive function (Table S1 in the Supplementary Appendix). However, some of these patients did not provide data for one or more of the substudy tests at the various follow-up points (Table 3, and Table S2 in the Supplementary Appendix). The rates of the primary outcome were lower among patients who agreed to participate in the substudies than among those who did not, but there was no interaction between substudy participation and group assignment with respect to the primary outcome (Table S3 in the Supplementary Appendix). There was a small decline in quality of life, as measured by the EQ-5D, in both groups at the time of discharge (Table 3), but this was followed by a sharp increase in perceived quality of life by patients in both groups at 30 days and at 1 year after surgery. There was no significant difference between the two groups in quality-of-life scores at any time point. There was less reduction from baseline in neurocognitive function, as assessed with the use of the Digit 


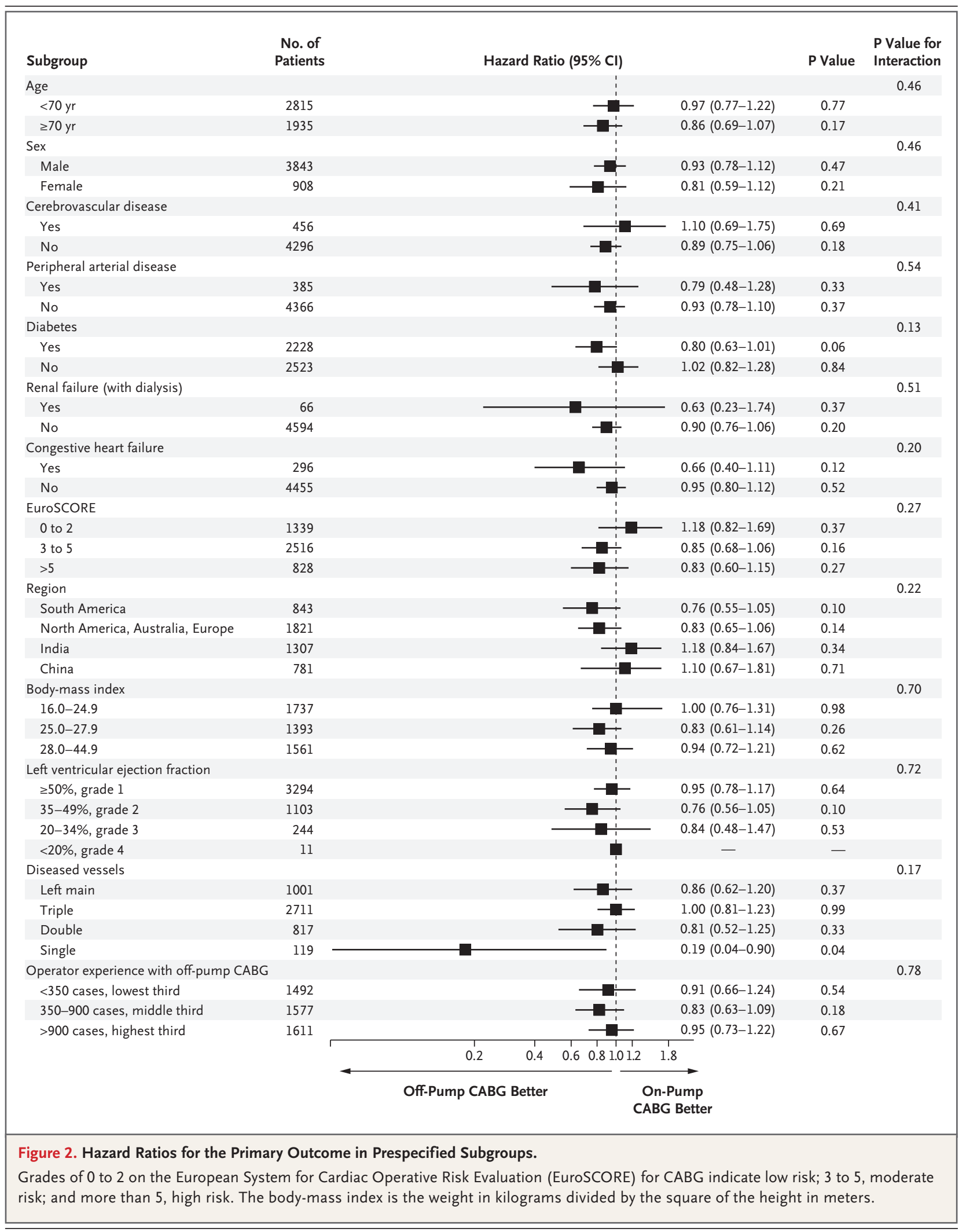

The New England Journal of Medicine

Downloaded from nejm.org at HAUPTBIBLIOTHEK UNIV ZUERICH on February 17, 2014. For personal use only. No other uses without permission. Copyright @ 2013 Massachusetts Medical Society. All rights reserved. 


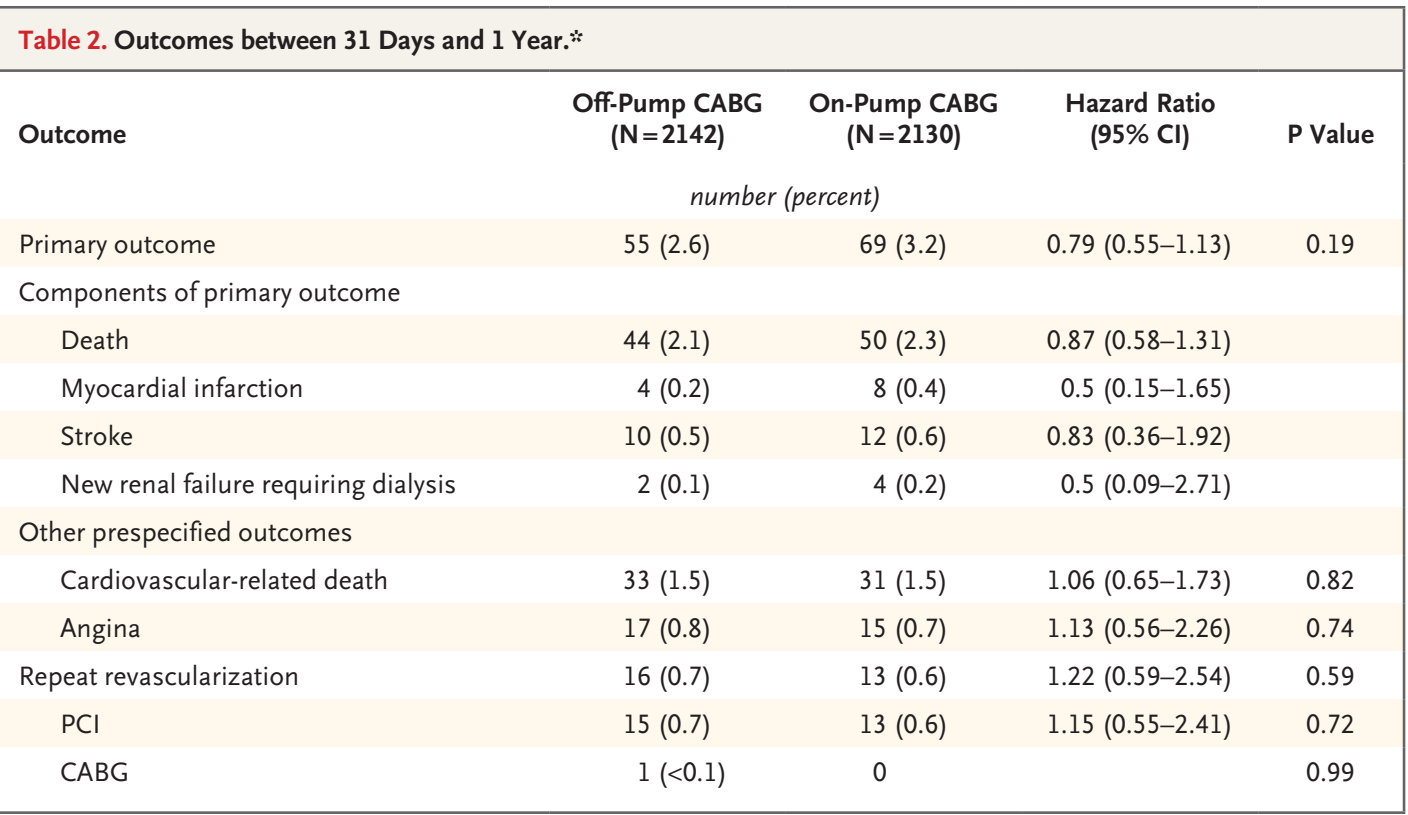

* The landmark analyses of data between 31 days and 1 year excluded data from patients who had a primary outcome in the first 30 days or who were not followed up after 30 days.

Symbol Substitution Test, in the off-pump group than in the on-pump group at discharge $(\mathrm{P}=0.04)$, but there was no significant between-group difference at 30 days or at 1 year. We found no differences between the two groups in the change in scores on the Montreal Cognitive Assessment or the Trail Making Test Part B. Sensitivity analyses comparing centers that had rates of participation in these assessments in the highest quartile with centers that had participation rates in the lower three quartiles also showed similar results (Table S4 in the Supplementary Appendix).

\section{DISCUSSION}

In this trial, we compared off-pump CABG with on-pump CABG in 4752 patients from 19 countries on five continents. We found no significant between-group difference at 1 year in the rate of the first coprimary outcome of death, nonfatal stroke, nonfatal myocardial infarction, or nonfatal new renal failure requiring dialysis; in the rate of each component of the coprimary outcome; or in the rate of repeat revascularization. Although there was a small difference in cognitive function in favor of off-pump CABG at discharge, this benefit did not persist at 1 year.

Our results differ from those of the ROOBY trial. ${ }^{7,8}$ That trial showed a significantly higher rate of the composite outcome at 1 year with offpump CABG than with on-pump CABG $(9.9 \%$ vs. $7.4 \%$; relative risk, 1.33 ; $95 \% \mathrm{CI}, 1.01$ to 1.76 ; $\mathrm{P}=0.04$ ), whereas there was no significant difference in CORONARY. There are important differences between the two trials. CORONARY included more than twice as many participants as were included in the ROOBY trial. In addition, the participants in our trial were enrolled at a diverse array of clinical settings, whereas the ROOBY trial recruited patients exclusively from the Veterans Affairs system. We specified a higher level of surgical expertise at the beginning of the trial than was required in the ROOBY trial; each operation was performed by a surgeon who had more than 2 years of experience and had completed more than 100 cases of the specific technique (either on-pump or off-pump CABG) to be performed. In CORONARY, trainees were not allowed to be the primary surgeon. The rate of crossover from off-pump to on-pump CABG was lower in CORONARY than in the ROOBY trial (7.9\% vs. $12.4 \%$ ), and the rate of repeat revascularization between 31 days and 1 year was also lower in CORONARY $(0.7 \%$ in the off-pump group and $0.6 \%$ in the on-pump group vs. $4.6 \%$ and $3.4 \%$, respectively, in the ROOBY trial), suggest- 


\begin{tabular}{|c|c|c|c|c|c|}
\hline \multirow[t]{2}{*}{ Measure } & \multicolumn{2}{|c|}{ Off-Pump CABG } & \multicolumn{2}{|c|}{ On-Pump CABG } & \multirow[t]{2}{*}{ P Value } \\
\hline & No. of Patients & Score & No. of Patients & Score & \\
\hline \multicolumn{6}{|l|}{ EQ-5D广ं } \\
\hline Baseline & 1424 & $0.77 \pm 0.22$ & 1421 & $0.77 \pm 0.22$ & 0.97 \\
\hline \multicolumn{6}{|c|}{ Change from baseline } \\
\hline To discharge & 1265 & $-0.03 \pm 0.28$ & 1251 & $-0.03 \pm 0.26$ & 0.75 \\
\hline To 30 days & 1154 & $0.07 \pm 0.26$ & 1161 & $0.08 \pm 0.25$ & 0.25 \\
\hline To 1 year & 1024 & $0.13 \pm 0.24$ & 1035 & $0.14 \pm 0.24$ & 0.25 \\
\hline \multicolumn{6}{|c|}{ EQ-5D visual-analogue scale } \\
\hline Baseline & 1423 & $65.8 \pm 17.6$ & 1422 & $66.6 \pm 17.8$ & 0.24 \\
\hline \multicolumn{6}{|c|}{ Change from baseline } \\
\hline To discharge & 1264 & $1.8 \pm 18.2$ & 1250 & $1.0 \pm 17.8$ & 0.26 \\
\hline To 30 days & 1154 & $8.5 \pm 17.6$ & 1159 & $8.0 \pm 17.6$ & 0.44 \\
\hline To 1 year & 1023 & $11.3 \pm 18.1$ & 1035 & $11.4 \pm 17.6$ & 0.88 \\
\hline \multicolumn{6}{|c|}{ Montreal Cognitive Assessment $[\widehat{J}$} \\
\hline Baseline & 1053 & $23.2 \pm 4.4$ & 1028 & $23.2 \pm 4.3$ & 0.90 \\
\hline \multicolumn{6}{|c|}{ Change from baseline } \\
\hline To discharge & 896 & $0.2 \pm 2.9$ & 881 & $0.1 \pm 2.9$ & 0.22 \\
\hline To 30 days & 797 & $1.0 \pm 3.1$ & 784 & $0.8 \pm 3.1$ & 0.26 \\
\hline To 1 year & 645 & $0.4 \pm 4.0$ & 628 & $0.3 \pm 4.0$ & 0.51 \\
\hline \multicolumn{6}{|c|}{ Digit Symbol Substitution Test $\rrbracket$} \\
\hline Baseline & 989 & $33.0 \pm 17.8$ & 986 & $31.9 \pm 18.0$ & 0.15 \\
\hline \multicolumn{6}{|c|}{ Change from baseline } \\
\hline To discharge & 812 & $-1.6 \pm 11.4$ & 797 & $-2.7 \pm 10.0$ & 0.04 \\
\hline To 30 days & 694 & $1.8 \pm 11.4$ & 685 & $1.3 \pm 10.8$ & 0.40 \\
\hline To 1 year & 522 & $1.8 \pm 13.2$ & 528 & $1.3 \pm 12.3$ & 0.56 \\
\hline \multicolumn{6}{|c|}{ Trail Making Test Part B\| } \\
\hline Baseline & 721 & $158.0 \pm 88.1$ & 711 & $163.7 \pm 89.5$ & 0.22 \\
\hline \multicolumn{6}{|c|}{ Change from baseline } \\
\hline To discharge & 523 & $5.2 \pm 55.4$ & 498 & $7.0 \pm 52.6$ & 0.59 \\
\hline To 30 days & 470 & $-10.9 \pm 58.1$ & 487 & $-4.7 \pm 71.2$ & 0.14 \\
\hline To 1 year & 353 & $-6.8 \pm 64.0$ & 340 & $-3.2 \pm 70.2$ & 0.49 \\
\hline
\end{tabular}

* Plus-minus values are means \pm SD. The number of patients at baseline indicates the number of patients who completed the baseline test. The number of patients at a subsequent time indicates the number of patients who completed the test at baseline and at that specific time.

$\uparrow$ The European Quality of Life-5 Dimensions (EQ-5D) questionnaire assesses five dimensions of quality of life. The total score ranges from 0 to 1 , with higher scores indicating better quality-of-life status.

The EQ-5D visual-analogue scale assesses the respondent's self-rated health on a vertical, visual analogue scale. The total score ranges from 0 to 100 , with higher scores indicating better health status.

$\int$ The Montreal Cognitive Assessment assesses executive function and detects subtle memory impairment. The total score ranges from 0 to 30, with higher scores indicating better cognitive function.

q The Digit Symbol Substitution Test was designed to assess differences among cognitively intact persons in a wide array of cognitive domains such as visual-motor speed and coordination, capacity for learning, capacity for sustained effort, attention, concentration, ability to imitate newly learned visual material, and short-term memory. The lowest score is 0 , and there is no upper limit; higher scores indicate better cognitive function.

$\|$ The Trail Making Test Part B is a test of scanning, visual-motor tracking, divided attention, and cognitive flexibility. The test is timed, and therefore a lower score (in seconds) indicates a better function. 
ing a higher level of surgical expertise in our trial. In both CORONARY and the ROOBY trial, the rates of the primary outcomes at 1 year among patients who underwent the assigned procedure (i.e., without crossing over to the other procedure) were consistent with those in the intention-to-treat analysis. In CORONARY, the rate of the primary end point was lower in the off-pump group than in the on-pump group (11.5\% and $13.2 \%$, respectively; $\mathrm{P}=0.08$ ), whereas in the ROOBY trial, the rate was lower in the on-pump group $(9.4 \%$ in the off-pump group vs. $7.1 \%$ in the on-pump group; $\mathrm{P}=0.08$ ).

It is possible that the relative success of the two procedures is influenced by the risk level of the patients, since new techniques tend to show benefits in patients at higher surgical risk, who have more to gain with newer, less invasive techniques. ${ }^{28,29}$ The participants in our trial were at a higher surgical risk than were patients in the ROOBY trial, as evidenced by the selection criteria, the baseline characteristics, and the 30-day mortality. In the ROOBY trial, the 30-day mortality was $1.6 \%$ in the off-pump group and $1.2 \%$ in the on-pump group. In contrast, the 30-day mortality in CORONARY was $2.5 \%$ in each group. The patients in CORONARY were older than were the patients in the ROOBY trial (mean age, 67.5 years vs. 62.7 years), and more patients in CORONARY required emergency surgery $(38.8 \%$ vs. $15.2 \%$ ). Our trial also included a group of patients with more complex coronary anatomy. As compared with the ROOBY trial, CORONARY included more women (19.2\% vs. $0.5 \%$ ), more patients with left main coronary artery disease ( $21.5 \%$ vs. 0 ), and more patients with three-vessel disease (after exclusion of patients with left main coronary artery disease) (74.2\% vs. $66.6 \%)$. In addition, $44 \%$ of the patients in CORONARY were of South Asian or East Asian ethnic groups, popu- lations that are known to have smaller coronary arteries. ${ }^{30-32}$ Therefore the apparent differences in results between the ROOBY trial and CORONARY may be due to differences in the baseline risk of the patients as well as the differences in the experience levels of the surgeons.

Our trial has some limitations. The quality-oflife and neurocognitive tests were optional, and some centers had low participation rates for these tests. We found that the patients who completed these tests were generally somewhat healthier than were patients who did not participate (Table S1 in the Supplementary Appendix). In addition, among patients who agreed to participate, many, despite our best efforts, refused to complete the more demanding neurocognitive tests. These tests could also not be completed if the follow-up was conducted only by telephone. Patients who chose not to participate initially or who refused to participate later during the follow-up period may differ in some ways from those who did participate. Although the possibility of a bias in favor of a particular technique cannot be excluded, various sensitivity analyses suggested that the results were robust and indicated little difference, if any, in quality of life or neurocognitive function between the patients in the two groups.

In conclusion, we conducted a large, randomized trial to compare the outcomes of on-pump CABG with off-pump CABG. At 1 year, we found no significant differences between the two groups in the rate of death, nonfatal stroke, nonfatal myocardial infarction, or nonfatal new renal failure requiring dialysis or in the rate of subsequent revascularization procedures. We also found no significant differences in quality of life or in neurocognitive function.

\footnotetext{
Supported by the Canadian Institutes of Health Research. Disclosure forms provided by the authors are available with the full text of this article at NEJM.org.
}

The authors' affiliations are as follows: The Population Health Research Institute, Hamilton Health Sciences, McMaster University, Hamilton ON (A.L., P.J.D., R.P.W., Y.O., J.P., S.C., S.Y.), Centre Hospitalier de l'Université de Montréal, Montreal (N.N.), and London Health Sciences Centre, London ON (R.J.N.) — all in Canada; Centre for Chronic Disease Control, New Delhi (D.P.), SAL Hospital and Medical Institute, Ahmedabad (A.R.J.), G. Kuppuswamy Naidu Memorial Hospital, Coimbatore (C.P.), Frontier Lifeline, Dr. K M Cherian Heart Foundation, Chennai (P.V.), Mediciti Hospitals, Hyderabad (S.K.R.), and All India Institute of Medical Sciences, New Delhi (B.A.) - all in India; University of Oxford, Oxford, United Kingdom (D.P.T.); Fu Wai Cardiovascular Hospital, Xicheng District, Beijing (S.H.); Instituto de Investigaciones Clínicas de Rosario, Rosario (E.P.), and Fundacion Medica de Rio Negro y Neuguen, Rio Negro (P.A.O.) - both in Argentina; Third Faculty of Medicine, Charles University, Prague, Czech Republic (Z.S.); Instituto Dante Pazzanese de Cardiologia, São Paulo (L.S.P.); Ankara University School of Medicine, Ankara, Turkey (A.R.A.); Hospital Regional Temuco, Temuco, Chile (J.-C.B.); Wuhan Asia Heart Hospital, Wuhan, Hubei, China (L.T.); and North Estonia Medical Center, Tallinn, Estonia (T.-A.S.). 
1. Yusuf S, Zucker D, Peduzzi P, et al. Effect of coronary artery bypass graft surgery on survival: overview of 10 -year results from randomised trials by the Coronary Artery Bypass Graft Surgery Trialists Collaboration. Lancet 1994;344: 563-70. [Erratum, Lancet 1994;344:1446.] 2. Sellke FW, DiMaio JM, Caplan LR, et al. Comparing on-pump and off-pump coronary artery bypass grafting: numerous studies but few conclusions: a scientific statement from the American Heart Association council on cardiovascular surgery and anesthesia in collaboration with the interdisciplinary working group on quality of care and outcomes research. Circulation 2005;111:2858-64.

3. Puskas JD, Williams WH, Mahoney EM, et al. Off-pump vs conventional coronary artery bypass grafting: early and 1-year graft patency, cost, and quality-oflife outcomes: a randomized trial. JAMA 2004;291:1841-9.

4. Nathoe HM, van Dijk D, Jansen EWL, et al. A comparison of on-pump and offpump coronary bypass surgery in lowrisk patients. N Engl J Med 2003;348: 394-402.

5. Légaré JF, Buth KJ, King S, et al. Coronary bypass surgery performed off pump does not result in lower in-hospital morbidity than coronary artery bypass grafting performed on pump. Circulation 2004; 109:887-92.

6. Straka Z, Widimsky P, Jirasek K, et al. Off-pump versus on-pump coronary surgery: final results from a prospective randomized study PRAGUE-4. Ann Thorac Surg 2004;77:789-93.

7. Novitzky D, Shroyer AL, Collins JF, et al. A study design to assess the safety and efficacy of on-pump versus off-pump coronary bypass grafting: the ROOBY trial. Clin Trials 2007;4:81-91.

8. Shroyer AL, Grover FL, Hattler B, et al. On-pump versus off-pump coronaryartery bypass surgery. N Engl J Med 2009; 361:1827-37.

9. Houlind $\mathrm{K}$, Kjeldsen BJ, Madsen SN, et al. On-pump versus off-pump coronary artery bypass surgery in elderly patients: results from the Danish On-Pump versus
Off-Pump Randomization Study. Circulation 2012;125:2431-9.

10. Houlind K, Kjeldsen BJ, Madsen SN et al. The impact of avoiding cardiopulmonary by-pass during coronary artery bypass surgery in elderly patients: the Danish On-pump Off-pump Randomisation Study (DOORS). Trials 2009;10:47.

11. van der Linden W. Pitfalls in randomized surgical trials. Surgery 1980;87:25862.

12. Song HK, Petersen RJ, Sharoni E, Guyton RA, Puskas JD. Safe evolution towards routine off-pump coronary artery bypass: negotiating the learning curve. Eur J Cardiothorac Surg 2003;24:947-52.

13. Brown PP, Mack MJ, Simon AW, et al. Comparing clinical outcomes in highvolume and low-volume off-pump coronary bypass operation programs. Ann Thorac Surg 2001;72:S1009-S1015.

14. Off-pump versus on-pump coronary bypass surgery. N Engl J Med 2004;350: 1791-3.

15. Lamy A, Devereaux PJ, Prabhakaran D, et al. Off-pump or on-pump coronaryartery bypass grafting at 30 days. $\mathrm{N}$ Engl J Med 2012;366:1489-97.

16. Lamy A, Devereaux PJ, Prabhakaran $\mathrm{D}$, et al. Rationale and design of the coronary artery bypass grafting surgery off or on pump revascularization study: a large international randomized trial in cardiac surgery. Am Heart J 2012;163:1-6.

17. Devereaux PJ, Bhandari M, Clarke M, et al. Need for expertise based randomised controlled trials. BMJ 2005;330:88.

18. The EuroQol Group. EuroQol - a new facility for the measurement of healthrelated quality of life. Health Policy 1990 16:199-208.

19. Brooks R. EuroQol: the current state of play. Health Policy 1996;37:53-72.

20. Hachinski V, Iadecola C, Petersen RC, et al. National Institute of Neurological Disorders and Stroke-Canadian Stroke Network vascular cognitive impairment harmonization standards. Stroke 2006;37 2220-41. [Erratum, Stroke 2007;38:1118.] 21. Nasreddine ZS, Phillips NA, Bédirian $\mathrm{V}$, et al. The Montreal Cognitive Assessment, MoCA: a brief screening tool for mild cognitive impairment. J Am Geriatr Soc 2005;53:695-9.

22. Kaplan E, Fein D, Morris R, Delis D. The WAIS-R as a neuropsychological instrument. San Antonio, TX: Psychological Corporation, 1991.

23. Fontbonne A, Berr C, Ducimetière P, Alpérovitch A. Changes in cognitive abilities over a 4-year period are unfavorably affected in elderly diabetic subjects: results of the Epidemiology of Vascular Aging Study. Diabetes Care 2001;24:366-70.

24. Hochstenbach JB, Anderson PG, van Limbeek J, Mulder TT. Is there a relation between neuropsychologic variables and quality of life after stroke? Arch Phys Med Rehabil 2001;82:1360-6.

25. Storandt M, Botwinick J, Danziger WL, Berg L, Hughes CP. Psychometric differentiation of mild senile dementia of the Alzheimer type. Arch Neurol 1984;41: 497-9.

26. Larrabee GJ, Largen JW, Levin HS. Sensitivity of age-decline resistant ("hold") WAIS subtests to Alzheimer's disease. J Clin Exp Neuropsychol 1985;7:497-504.

27. Saczynski JS, Marcantonio ER, Quach L, et al. Cognitive trajectories after postoperative delirium. N Engl J Med 2012; 367:30-9.

28. Smith CR, Leon MB, Mack MJ, et al. Transcatheter versus surgical aortic-valve replacement in high-risk patients. $\mathrm{N}$ Engl J Med 2011;364:2187-98.

29. Kodali SK, Williams MR, Smith CR, et al. Two-year outcomes after transcatheter or surgical aortic-valve replacement. N Engl J Med 2012;366:1686-95.

30. Makaryus A, Dhama B, Raince J, et al. Coronary artery diameter as a risk factor for acute coronary syndromes in AsianIndians. Am J Cardiol 2005;96:778-80. 31. Lip GY, Rathore VS, Katira R, Watson RD, Singh SP. Do Indo-Asians have smaller coronary arteries? Postgrad Med J 1999; 75:463-6.

32. Dhawan J, Bray CL. Are Asian coronary arteries smaller than Caucasian? A study on angiographic coronary artery size estimation during life. Int J Cardiol 1995;49:267-9.

Copyright $\odot 2013$ Massachusetts Medical Society.

RECEIVE IMMEDIATE NOTIFICATION WHEN AN ARTICLE

$$
\text { IS PUBLISHED ONLINE FIRST }
$$

To be notified by e-mail when Journal articles are published Online First, sign up at NEJM.org. 